\title{
Specific Characteristics of Bioelectric Activity of the Brain in Women with Placental Dysfunction Considering the Type of Psychological Component of Gestation Dominant
}

\author{
Nataliya Henyk, Nataliya Yakymchuk
}

\begin{abstract}
The study of the influence of the autonomic nervous system on the course of pregnancy, childbirth and fetal state remains relevant. Changes in the parameters of electroencephalography may be detected long before the onset of clinical symptoms in the complicated course of pregnancy.

The objective of the research was to evaluate electroencephalography in women with placental dysfunction and gestational complications taking into account the type of psychological component of gestation dominant.

Materials and methods. Electroencephalography was performed in 60 pregnant women at the age of 19 to 45 years with gestational hypertension and fetal distress during pregnancy. The main group included 40 patients, who were stratified according to the type of psychological component of gestation dominant: 10 patients with euphoric type, 20 pregnant women with anxious and depressive type, 10 patients with hypogestognostic type. The comparison group comprised 20 patients with optimal type of psychological component of gestation dominant and normal course of the first half of pregnancy. The assessment of psychological component of gestation dominant was carried out according to the method proposed by Dobriakov I.V. - "Pregnant woman attitude test". Registrations, spectral and coherent analysis of electroencephalography were performed using BrainTest-24 hardware and software complex.

Results and discussion. Electroencephalography of the patients of the comparison group was in line with current concepts regarding the physiological norm. In the main group, there were the following changes in electroencephalography: nonsinusoidal forms of alpha-oscillations $(77.5 \%)$, high index of fast rhythms, flashes of spike waves under load, disturbances of the frontal occipital gradient with the focus on the anterior sections of the hemispheres.

Conclusions. The use of electroencephalography in women with different types of psychological component of gestation dominant in case of progressive placental dysfunction and preeclampsia on its background allows identifying characteristic changes, modifying the program of therapeutic measures, differentiating obstetric tactics and terms of delivery.
\end{abstract}

Keywords

autonomic nervous system; psychological component of gestation dominant; placental dysfunction; electroencephalography

Ivano-Frankivsk National Medical University, Ivano-Frankivsk, Ukraine

*Corresponding author: nataliya.yakumchuk@gmail.com

\section{Problem statement and analysis of the latest research}

The psycho-emotional state of pregnant women along with other obstetric and gynaecological and somatic factors plays a significant role in the etiopathogenesis of gestational complications [1]. Increased anxiety, mental exhaustion and asthenic symptoms cause a decrease in the stress resistance of the organism, lead to changes in the autonomic status and the formation of autonomic dysfunction [2]. As a result, the stressful psycho-emotional status at the stage of the preconception preparation arranges a background that initiates the pathological course of pregnancy and the development of placental dysfunction, premature delivery, preeclampsia and antenatal hypoxia of the fetus.
During pregnancy, all functions of the body undergo changes and adaptive reorganization, which leads to the activation of the autonomic nervous system (ANS) as one of the most significant in providing compensatory processes in motherplacenta-fetus systems [3]. According to a number of studies, the ANS is severely stressed in the process of pregnancy due to the anatomical and functional affinity of higher autonomic centers, structures of psycho-emotional regulation and centers for the regulation of reproductive function [4].

The degree of defect severity determines the course of pregnancy, labour and the state of the newborn; the dysfunction of this system can cause disadaptation of adequate hormonal, immune and homeostatic state of a pregnant woman\&rsquo; s body [5, 6]. Considering the role of the ANS in the forma- 
tion of emotions, the study of the psycho-emotional state of pregnant woman in case of complicated pregnancy, taking into account different types of psychological component of gestation dominant (PCGD) is of particular interest. Scientific research data concerning this problem are rather controversial and insignificant nowadays [7].

According to the literary, the characteristics of the bioelectric activity of the brain is reflected in the mechanisms that provide adaptive and regulatory responses and conditions at different levels of the central nervous system (CNS) [8]. In addition, in case of complicated course of pregnancy, changes in electroencephalography (EEG) parameters may occur long before the onset of clinical symptoms [9], whereas a timely diagnosis of the brain tissue dysfunction in women with different types of gestation dominant, in our opinion, may create preconditions for modifying the preconception preparation program and applying adequate therapeutic measures in the process of monitoring pregnancy.

The objective of the research was to evaluate the electroencephalographic parameters that characterize disturbances in the functioning of the CNS in women with placental dysfunction and gestational complications on its background, taking into account the type of PCGD.

\section{Materials and Methods}

Electroencephalographic examination was performed in 60 pregnant women at the age of 19 to 45 years with gestational hypertension and fetal distress. The main group consisted of 40 patients, who were stratified according to the following types of PCGD: 10 patients with euphoric type, 20 pregnant women with anxious and depressive type, 10 patients with hypogestognostic type. The comparison group consisted of 20 patients with optimal type of PCGD and the physiological course of the first half of pregnancy.

Exclusion criteria were craniocerebral trauma, epilepsy, history of mental illnesses, severe somatic pathology and the patient\&rsquo; s refusal to participate in this research.

The experimental psycho-diagnostic study was conducted by a certified psychologist in the Centre for the Conscious Paternity "Divia" on a voluntary basis. The study included women at different stages of pregnancy. The assessment of PCGD was carried out according to the method proposed by Dobriakov I.V. - "Pregnant woman attitude test" [10]. To evaluate the state of the ANS, a computer cardiointervalography with the study of the parameters of variational pulsometry and spectral analysis was used. In parallel, the psychodiagnostic "Dating Questionnaire" and projective drawing method "Me and My Child" by Filipova G.G. were carried out with the aim of clarifying and obtaining more reliable data [11]. Registrations, spectral and coherent analysis of EEG were performed using BrainTest-24 hardware and software complex. There were used the monopolar EEG registration method and the "10-20" scheme in the symmetrical frontal, temporal, central, parietal and occipital areas at rest with closed eyes for $15 \mathrm{~min}$ utes in the frequency band from 0.1 to $30 \mathrm{~Hz}$ and the frequency of the $160 \mathrm{~Hz}$ digital analogue discretization for each of 14 channels. The result of the recording was evaluated visually and using the spectral analysis. The visual analysis included evaluation of the severity of dysfunction changes in the bioelectric activity of the brain, the presence of local disturbances of corneal electrogenesis, the degree of severity of the basic rhythm, the characteristics of the alpha rhythm (frequency, amplitude, severity of modulation), stability and waveform shape of oscillations (sinusoidal or spike, frontal occipital gradient), the characteristics of the beta rhythm (severity, zonal distribution, frequency and amplitude), the presence of slowwave activity of the theta and delta ranges and the nature of the distribution, the regional amplitude differences, the presence of epileptiform activity. The calculation of the power and coherence spectra was performed in the frequency range of theta $(4-7 \mathrm{~Hz})$, alpha $(8-13 \mathrm{~Hz})$ and beta (14-30) rhythms of EEG. Then, the average values of EEG power spectrum for each allocation, as well as the coherence of electrograms in all rhythmic ranges of leads were calculated. Statistical analysis of EEG spectral characteristics, as well as the coherence indicators was performed using multivariate dispersion analysis in the standard package of software programs Statistics 6.

\section{Results and Discussion}

It should be noted that despite numerous studies of this problem, information on autonomic regulation during high-risk pregnancies is not sufficiently specified and insignificant, which explains the relevance of studying the effect of the ANS on the course of pregnancy, childbirth and fetal status. In our study, the confirmation of the role of the ANS in the group of patients suffering from gestational hypertension with anxious and depressive type of PCGD served a decrease in the heart rate variability in comparison with healthy pregnant women, which could be regarded as a result of excessive activity of the sympathetic division of the ANS in this category of patients [1]. The study demonstrated autonomic dysfunction in $2.5 \%$ of patients; the prevalence of parasympathicotonia and the decline in the reactivity of the ANS was noted. At the same time, the study of the psycho-emotional status showed an increased level of asthenia, depression, anxiety and hypochondria. Patients with euphoric type of PCGD and hypertensive disorders at rest and during physical activity showed higher sympathetic activity and lower parasympathetic activity.

The analysis of bioelectric activity of the brain demonstrated that EEG in patients of the comparison group ("physiological pregnancy") corresponded to modern ideas regarding the physiological norm. When comparing the characteristics of the background activity of patients in the main group, it should be noted that there was a significant difference in the interpretation of EEG results, namely: the dominance of alpha rhythm in patients with anxious and depressive type of PCGD (85.0\% of women vs. $15.0 \%$ of women in the comparison group, p\&lt; 0.05), non-sinusoidal forms of alpha-oscillations (77.5\% of women of the main group), high index of fast rhythms, flashes of spike waves under load, disturbances of 
the frontal-occipital gradient with the focus on the anterior sections of the hemispheres.

It should also be noted that the regional amplitude differences were smoothed in $62.5 \%$ of patients of the main group as compared to $15.0 \%(n=3)$ of the examined women in the comparison group; in $7.5 \%(\mathrm{n}=3)$ of pregnant women (with depressive type of PCGD), there were observed epileptiform complexes, while such cases were absent in the comparison group, and pathological forms of bioelectric activity were expressed mainly in the anterior-temporal areas of the brain.

In the main group, the frequency of biliary and synchronous activity of the alpha frequency range, the decrease in the power of the alpha range of the occipital and parietal lobes, and the increase in the beta range in the anterior-temporal areas prevailed by practically 2.0 times as compared to the data of the comparison group.

The obtained results testified to the presence of significant changes in the cranial bioelectric activity in women with gestational hypertension and fetal distress during pregnancy in correlation with certain types of PCGD, namely: anxious and depressive types. The disorganization of alpha rhythm, spike alpha-oscillations, and increased beta-band strength were the reflection of the excitation and activation of the reticulo-cortical system of such women. The activation of the limbic-cortical system was indicated by the synchronous theta activity in the anterior regions of the cerebral cortex and the accompanying increase in the power spectrum of the theta range, while the increase in bilaterally-synchronous slow-wave activity reflected the involvement of the reticulo-cortical system in this process. The activation of the thalamic-cortical system and the activating effect of the mesencephalic reticular formation were evidenced by the synchronization of alpha rhythms and their spatial redistribution with disturbances of zonal differences, as well as reduction in the power spectrum in the occipital and parietal lobes. The most prognostically undesirable EEG symptom complex during gestational hypertension on the background of placental dysfunction is the appearance of spike waves and spike wave - slow wave complexes being typical for brain oedema and convulsive readiness. The differences in the analysis of EEG reflected the impaired integration between nonspecific activating and synchronizing systems of the brain, that disturbed the mechanisms of brain homeostatic adaptation. According to the analysis of EEG in pregnant women with anxious and depressive type of PCGD on the background of complicated gestational hypertension during pregnancy as compared to the group of patients with a physiological norm, there were significant differences in coherence parameters with a decrease in their levels in the range of fast frequencies, which was closely related to the data of the existing research concerning the role of neurogenic factors in the development of gestational complications, in particular preeclampsia $[9,10]$.

For healthy pregnant women, a typical nature of EEG correlation with a high level of interconnection of the cerebral hemispheres is characteristic. Patients with complicated preg- nancy, especially those with anxious and depressive type of PCGD, are characterized by significantly lower coherence in the alpha band frequencies of the temporal and central areas on the background of its weakening in other frequency bands (the maximum differences are observed in the left hemisphere), which may reflect the enhancement of activating influence of limbic-diencephalic structures due to the increase in afferent impulses from the area of the mild-placental complex, namely pathological stable connections of non-cortical structures are formed, that disturbs its co-operative functioning in this category of patients.

The conducted studies revealed cases of more favourable course of pregnancy in patients with hypertension, namely the activation of protective mechanisms of adaptation of the somnogenic type. The progression of gestational hypertension was characterized by significant strain of adaptive mechanisms of the brain that manifested itself as a high level of anxiety, hormonal, immune and metabolic disorders, as well as low-amplitude type of electroencephalogram or the presence of high-amplitude background alpha rhythm. Patients with severe pregnancy course and depressive type of PCGD (pregnancy ended with preterm birth or negative perinatal consequences) were characterized by the strain of brain adaptive mechanisms. It should be noted that the complications depended on the type of autonomic dysfunction. Thus, in the somatoform disorders of the ANS of the hypotonic type, the pregnancy was more often complicated by gestational oedema, and in the somatoform disorders of the ANS of the hypertonic type, it was complicated by the risk of preterm birth, severe preeclampsia and fetal distress.

Thus, despite the contradictory opinions concerning the state of the ANS and its role in the genesis of gestational complications, the results obtained confirmed changes in the functional tonus of the ANS divisions in patients with different types of PCGD. On the one hand, inadequate autonomic regulation of the tonus in the ANS division of women with euphoric, anxious and depressive type can be a factor that initiates gestational complications, and, on the other hand, it is a marker of the maternal health problems. The characteristics of the ANS can be used as a criterion for assessing the pathogenetic mechanisms of pregnant woman adaptation that offers us new perspectives in treating pathology in pregnancy by affecting the CNS.

\section{Conclusions}

Thus, the use of EEG in women with different types of PCGD in case of progressive placental dysfunction and preeclampsia on its background allows identifying characteristic changes in bioelectric activity of the brain, while the quantitative characteristics of the reactions in patients with anxious and depressive type of PCGD and co-existent abnormalities in the neurological status serve as a prognostic value, that allows modifying the program of therapeutic measures, differentiating obstetric tactics and terms of delivery. 


\section{References}

[1] Aleksandrov LS, Kovalev MI, Maslankina KP, Tutter NV. Importance of the vegetative nervous system condition for course of pregnancy, labor and neonatal period. Akusherstvo i ginekologiya. 2013;02:62-66. [published in Russian]

[2] Vasilyeva VV. Mekhanizmy formirovaniya i funktsionirovaniya reproduktivnykh dominant $\mathrm{v}$ spontannykh i stimulirovannykh tsiklakh. Fiziologiya cheloveka. 2010;3:55-65.

[3] Smirnov AG, Batuyev AS et al. Osobennosti EEG u zhenshchin pri oslozhnennykh formakh protekaniya beremennosti. Fiziologiya cheloveka. 2001;1:42-52.

[4] Vasilyeva VV, Bondarenko UE, Krynochkina MU. Spektralnyye kharakteristiki bioelektricheskoy aktivnosti mozga u beremennykh s sindromom gipeandrogeniyi $\mathrm{v}$ anamnenze. Valeologiya. 2010;3:14-18.

[5] Verbitskaya MS, Zakharichuk YuV. Vliyaniye psikhosomaticheskogo statusa na techeniye beremennosti, rodov i poslerodovogo perioda. Psikhoterapiya i klinicheskaya psikhologiya. 2010;1:91-98.

[6] Fedotchev AI, Kim EV. Characteristics of EEG-based biofeedback treatment procedures in normal and complicated pregnancy. Zhurnal vysshey nervnoy deyatelnosti. 2009;59(4):421-428. [published in Russian]

[7] Vorobey LI. Current aspects of obstetrical and perinatal complications prevention in women with perinatal losses in history. Simeina medytsyna. 2016;3:148-152. [published in Ukrainian]

[8] Brusse IA, Peters NC, Steegers E et al. Electroencephalography during normotensive and hypertensive pregnancy: a systematic review. Obstet Gynecol Surv. 2010;65:794-803. DOI: https://doi.org/ 10.1097/OGX.0b013e31821286f1

[9] Kudinova VV. Prohnozuvannia platsentarnoii nedostatnosti $\mathrm{z}$ rannikh terminiv vahitnosti iz zastosuvanniam system shtuchnoho intelektu. Reproduktyvne zdoroviia zhinky. 2007;4(33):92-94.

[10] Eidemiller EG, Dobryakov IV, Nikolskaya IM. Semeynyy diagnoz i semeynaya psikhoterapiya. Uchebnoye posobiye dlya vrachey i psikhologov. SPb; c2006. 352p.

[11] Hasiuk MB, Ishchuk OYu, Shevchuk HS. Vykorystannia psykhomaliunku dlia psykholohichnoii pidhotovky vahitnoii zhinky do polohiv (30-40 tyzhni vahitnosti). Psykholohiia i suspilstvo. 2006;3:140-148.

Received: $2018-10-26$

Revised: 2018-11-05

Accepted: 2018-11-05 